\title{
The value of knowledge sharing: impact of tacit and explicit knowledge sharing on team performance of scientists
}

\author{
Bojan Obrenovic $^{1 *}$ Slobodan Obrenovic ${ }^{2}$ Akmal Hudaykulov ${ }^{1}$ \\ 1 School of Management, Wuhan University of Technology, Wuhan, P.R.China, 430070 \\ 2 Inovatus Usluge Ltd., Zagreb, Croatia, 10000 \\ *E-mail of the corresponding author:obrenovic.bojan@gmail.com,
}

\begin{abstract}
Knowledge sharing that takes place among team members is a process of great relevance that builds ties and relationships which in turn results in positive organizational and team outcomes. However, as it is not usually formally included in the job descriptions and is not a formal part of organizations' and team activities, it is considered to be an organization citizenship behavior. Our paper emphasizes significance of tacit and explicit knowledge sharing to team performance in the context of scientific cooperation. A positive relationship between tacit knowledge sharing and explicit knowledge sharing with team performance was found using linear regression. Furthermore, high levels of knowledge sharing and team performance were identified among scientists.
\end{abstract}

Keywords: Team performance, Knowledge sharing, Tacit knowledge, Explicit knowledge, Scientific cooperation

\section{Introduction}

A new perspective of a "knowledge-based view of the firm" (Dyer and Nobeoka, 2002), that knowledge is the most important organizational resource has emerged. Scholars suggest that the key role of the firm is in creating, storing, and applying knowledge (Kogut \& Zander, 1992; Conner\& Prahalad, 1996; Grant, 1996) Knowledge sharing is an additional activity that firm should focus on. As a concept knowledge sharing has been recognized as significant tool for increasing knowledge (Alavi \& Leidner, 2000). Plenty of research aimed at investigating various factors contributing to knowledge sharing in recent years, mainly because when knowledge is being shared the collective memory of the organization is being enhanced, which leads to better organizational performance. By sharing knowledge employees contribute to the knowledge base, innovativeness and ultimately competitive advantage of their organization (Jackson et al., 2006) and the success of a project (Adenfelt, 2010). Furthermore, knowledge sharing that takes place among team members is a process of great relevance that builds ties and relationships which in turn enhance team performance. However, as it is not usually formally included in the job descriptions and is not a formal part of organizations' and team activities, it is considered to be an organization citizenship behavior. Nevertheless, its role is crucial for teams, projects' and organizations' success.

Team performance as an outcome of knowledge sharing has to some extent been investigated in the prior literature however not in the context of scientific cooperation, and not as an outcome of sharing of explicit and tacit knowledge. For that reason, we divide knowledge sharing into tacit and explicit to investigate whether team performance of scientists is contingent on both explicit and tacit knowledge sharing. Additionally, we will evaluate the current level of knowledge sharing on the projects in question. Even among scientists, who are assumed to share their knowledge freely as they are engaged in knowledge intensive activities that require close cooperation, certain barriers can exist, sometimes reflecting the surrounding environment which does not foster positive characteristic and natural principles of science. Sometimes in the dynamic working environment characterized by geographic dispersion, electronic dependence, dynamic structure and national diversity of its members (Gibson and Gibbs, 2006) difficulties might occur. In such working environments due to the cultural diversity, language obstacles, task organization, lack of face-to-face interaction and geographical dispersion there is a lack of shared identity, sense of belonging and trust in others (Au and Marks, 2012). Consequently, misunderstanding and conflict between team members might occur (Richards and Bilgin, 2012), all which can hinder knowledge sharing. Still, work of scientists on various projects implies close cooperation and knowledge sharing, and so it can present a benchmark on knowledge sharing for other project and organizational teams. In order to conduct a deeper investigation of factors that influence knowledge sharing we should firstly determine its importance to the team performance in the context of our projects. 
To author's knowledge there has been no systematical analysis of nationally financed projects in Croatia up to this point. Furthermore, there have been no studies conducted in the context of knowledge sharing. The general objective of this study is to evaluate the current state of knowledge sharing and team performance in joint research projects between Croatia and other countries and at the same time determine the influence of explicit knowledge sharing and tacit knowledge sharing on team performance. Moreover, most of the prior studies do not distinguish between sharing of tacit and explicit knowledge, and did not investigate projects characterized by a dynamic labor environment.

\section{Literature review}

On the individual level knowledge sharing is considered to be a significant process resulting in positive organizational outcomes, such as superior innovation capability, work-environment creativity (Schepers and van den Berg, 2007), team performance cohesion, knowledge integration and decision satisfaction (Mesmer-Magnus et al., 2009).

As a result in the extensive research on knowledge management individual knowledge sharing has justifiably held an important position and therefore has been a subject of many studies. In those studies knowledge is usually divided into two types: explicit and tacit. Explicit knowledge usually refers to the type of knowledge that can easily be communicated with words, codified and subsequently shared. Explicit knowledge is easy to capture and usually comes in a somewhat tangible form, generally as documents, PPTs, manuals. Sharing of explicit knowledge is usually being facilitated by information technology. Tacit knowledge or know-how (Kogut and Zander, 1992; Grant, 1996;) on the other hand is related to an individual's experience and thoughts (Alavi \& Leidner,2001)and is subject to social interaction (Käser \& Miles, 2002; Nonaka, 1994) and friendship (Osterloh \& Frey, 2000). Team members' sharing of tacit knowledge is reinforced in situations in which they interact faceto face in the context of project work. (Howells, Jeremy, 1996). Geographical proximity of team members, common language and mutual trust all affect the level of tacit knowledge utilization on projects, which can in turn affect team performance. (Koskinen, Pihlanto \& Vanharanta, 2003).According to the SECI model, illustrating knowledge creation, developed by Nonaka and Takeuchi, a nonstop interaction between individuals occurs in which knowledge is being continuously converted from tacit to explicit and from explicit to tacit. SECI process is comprised of four knowledge creation modes: socialization (tacit to tacit), combination (explicit to explicit), externalization (tacit to explicit), and internalization (explicit to tacit). As tacit knowledge is internal, and embedded in people, human interactions are essential for its transfer. So in the socialization process tacit knowledge in the form of experience or skills can be transferred between individuals.

Externalization, on the other hand is a process of making tacit knowledge explicit. For example, organizations will try to capture what the employees know through creating platforms where they can interact and share knowledge, usually internal forums for communities of practice where they can exchange knowledge. Through synthesizing the body of knowledge, to some extent, but not fully will the process of externalization be successful. Early knowledge management practice and research have been mostly focused on managing explicit knowledge in forms of documents, forms, procedures and etc. creating huge repositories of knowledge and relying on IT to facilitate knowledge sharing processes, and enhance the collective memory of an organization However the assumption that when technology for knowledge sharing is implemented that employees will share knowledge is showed to be false, and often failed to make tacit knowledge explicit due to the cognitive nature of tacit knowledge (Pawlowski and Robey, 2004). Sharing of knowledge does not only depend on the technology factor but on many others. Furthermore, technology itself often fails to capture the most important component of knowledge, the tacit one. Our efforts are aimed at examining both sharing of tacit and explicit knowledge. We posit that sharing of information and codified knowledge facilitated by information technology, especially on the projects which are to some extent virtual, as well as tacit knowledge, ingrained in daily routines and embedded in people through the process of socialization are relevant for team performance. Based on this proposition we build our research model.

\section{Research model and hypotheses}

In the establishment of our research model we tested the influence of both tacit and explicit knowledge sharing on team performance. We also posit that scientists intensively share both tacit and explicit knowledge, consequently resulting in high team performance. Prior research has widely demonstrated positive effects of knowledge sharing on team performance (Argote and Ingram 2000; Cummings 2004; Hansen 2002; Choi et al., 2010). 


\subsection{Knowledge sharing and Team performance}

\subsubsection{Explicit knowledge sharing}

Explicit knowledge sharing encompassing various formal and systematically stored, articulated and disseminated information (Becerra-Fernandez \& Sabherwal, 2001) is beneficial for workers, teams and organizations. However often redundancy of information is present, as these systems accumulate wide knowledge, still with proper filtering mechanisms used to distinguish relevant from irrelevant knowledge, team members and workers can easily get required information. Organizations have built systems for managing explicit knowledge, knowledge platforms document repositories, search engines and intranets (Hansen and Haas 2001) making information widely available and easily accessible.). In their study.... indirect influence of knowledge sharing through knowledge application was found, but no direct effect of knowledge sharing on team performance (Choi et al.,2010). Through the means of IT support collaboration and communication contributing to the building of TMS in teams is fostered. (Choi et al., 2010).

As a result team members can decrease the time of search and creation by quickly accessing and using collective knowledge made explicit, which in turn will enhance their individual efficiency and consequently team performance.

Many studies have shown relationship between effective explicit knowledge sharing, or information sharing and team performance (Greenhalgh \& Chapman, 1998; Schittekatte \& Van Hiel, 1996). According to the metaanalysis on information sharing conducted by (Mesmer-Magnus et al., 2009) two characteristics of sharing are relevant. Meta-analytic results from 72 studies show the positive link of information sharing to team performance, cohesion, decision satisfaction, and knowledge integration.. By using distinctive knowledge from their members in order to gain advantage, they will enlarge the knowledge fund which would enhance team task performance. Secondly, the concept of openness in explicit knowledge sharing could provide more opportunities to share unique knowledge and contributing to the trusting climate which would improve team socio-emotional outcomes and in turn team task performance (Beal, Cohen, Burke, \& McLendon, 2003).

\subsubsection{Tacit knowledge sharing}

Via sharing of tacit knowledge which is embedded in people, individuals provide their valuable knowledge and tap into what others know. Tacit knowledge has a crucial role in the organizational performance improvement (Small and Sage, 2006; Reychav and Weisberg, 2009). Through the process of socialization knowledge can be transferred from one person to another. Expertise, skills or experience which are difficult to capture and codify can be shared through creating mentoring programs or various workshops which will create shared mental modes that would ease the coordination and collaboration process resulting in better utilization of knowledge and higher team performance (Marks et al., 2000).

Transactive memory of "who knows what" has had a positive relationship with team performance due to improved coordination (Wegner et al., 1987). Transactive memory system (TMS) refers to a shared mental mode of the collective indicating which individuals know certain things and which individuals know who knows certain things (Jarvenpaa and Majchrzak, 2008) and it encompasses encoding, storage, and retrieval of knowledge from different spheres (Wegner et al., 1987) Through building a transactive memory system specialization of knowledge together with trust in knowledge of others and knowledge coordination according to the task structure are achieved (Wegner et al.,1987). Elements of knowledge sharing, such us feedback, communication influence the development of TMS (Hollingshead 1998a, 1998b; Moreland et al., 1996) which in turn enhances team performance (Liang et al., 1995; Lewis \& Kyle, 2004; Kanawattanachai \& Yoo, 2002; Faraj \& Sproull, 2000).

Having an insight in the knowledge of others, a best practice can be recognized and implemented by other individuals. Also, the shortening of a learning curve for younger scientists would lead to higher efficiency and improved team performance. In the environment where people are trusting, open, interacting and share their tacit knowledge without the fear of losing their own unique value, can result in higher collective performance (Käser \& Miles, 2002) and building of a strong team identity and positive team characteristics that can lead to a superior team performance and in turn generate positive outcomes, such as innovation or financial performance, either in the context of projects or organizational context. Tacit knowledge is considered an important source of competitive advantage for individuals, teams and organizations as it is specific to the context, personal and thus hard to imitate (Berman, Down, \& Hill, 2002).

Taking all the ample evidence into consideration on the existing relationship between knowledge sharing and team performance, we posit that in the context of scientific project cooperation significance is present. 
Therefore we hypothesize:

H1 Sharing of tacit knowledge positively influences Team performance

H2 Sharing of explicit knowledge positively influences Team performance

3.3.3 Level of knowledge sharing and team performance

Team performance has exhibited its value in the context of innovation, competitive advantage, quality etc., and has received much attention in the prior research (Cohen \& Bailey 1997).For project work teams are usually constructed and play an important role in knowledge-based organizations as they are often utilized to work on complex tasks (Cummings 2004; Rico et al. 2008). As knowledge has been recognized as a driver of innovation and a strategic asset, and in knowledge intensive groups and companies it has taken a central role in team performance. Knowledge workers on such projects are participating in intensive knowledge tasks, solving complex problems, have a high education and therefore through their collaborative efforts enhance team performance and drive innovation and other positive organizational outcomes. Knowledge workers tend to demonstrate flexibility, initiative, and higher job performance (Stewart \& Barry, 1997; Davenport \& Prusak, 1998). In a study of knowledge acquisition variables on financial and non-financial team performance, there was a positive relationship found, especially with a communication understanding component (Politis, 2003).

In the context of scientific work knowledge sharing can hardly be put in the domain of organizational citizenship behavior. As for scientists tacit knowledge sharing is a matter of daily practice, in which they engage in knowledge intensive activities which require collaboration. Conducting experiments in the laboratory, use of equipment, close cooperation, joint publications and presentations of the project result, all encompass both sharing of tacit and explicit knowledge and are necessary for project completion. As scientists are characterized by a strong passion for practice and as knowledge sharing in the case of science projects cannot be considered organizational citizenship behavior. Free flow of knowledge and openness are basic principles of scientific cooperation, as science can be advanced through complete transparency and sharing.

Based on this we hypothesize:

H3 Tacit knowledge sharing level between scientists is high

H4 Explicit knowledge sharing between scientists is high

H5 Team performance is high

\section{Research methodology}

In our investigation we applied a survey method by which we examined a sample of 277 members of project teams working on international science and technology research projects. Sample includes knowledge-intensive projects aimed to solve complex problems through innovative solutions for which knowledge sharing is highly relevant. We focused on investigating international science and technology project team members' interaction and knowledge sharing. During the projects the scientists from different countries worked together (from several months to several years) involved in knowledge intensive activities aimed to result in relevant scientific findings. Employees of research institutes and universities in Croatia were mostly the participants in international science and technology projects involved in projects from semiconductor industry, information technology, electronics, photonics, petrochemicals, medical science, and biochemistry. With the intention of avoiding the threat of common method bias data was collected from two different sources, both project managers and project team members. Approximately $55 \%$ of the team members in the final sample were male. A majority of the group members $(71 \%)$ were between the ages of 30-49. Ninety-five percent of the members had a college degree and $50 \%$ of the members had a Master's or Doctoral degree. Most of the group members' tenure $(68.8 \%)$ was over twenty years. Team members were working utilizing IT and face to face on a daily basis. The sample included the FP7, bilateral and multilateral project members of Croatian nationality.

\subsection{Measurement development}

All the variables were operationalized and measured with existing scales which were validated by other researchers. To normalize the data, we adjusted the scale wording so all items were measured with a 7 point Likert scale with anchors being $1=$ strongly disagree, $2=$ somewhat disagree, $3=$ disagree, $4=$ neutral, $5=$ somewhat agree, $6=$ agree, $7=$ strongly agree 
The constructs in our study were measured with items adopted from previous studies utilizing already developed scales.

\subsubsection{Team performance}

Team performance was measured with the adjusted scale of Baruch and Lin (2012) who adopted the measurements for Team performance from Stewart and Barrick (2000). Both team behaviors and team outcomes make up team performance and were included in the original version of scale measuring. In our study we assessed quality of work, quantity of work, planning and allocation of resources, overall team performance. Items that were dropped from the original measurement included interpersonal skills, knowledge of tasks, initiative and commitment to the team.

\subsubsection{Explicit and Tacit knowledge sharing}

We assessed explicit and tacit knowledge sharing with items adopted from Wang and Wang (2012) who reported that they operationalized explicit and tacit knowledge sharing variable by combining items from multiple sources (Reychav \& Weisberg, 2010; Liebowitz, 1999; Alavi \& Leidner, 2001) in order to capture the essence of the constructs. Six-item scale used to measure explicit knowledge sharing was slightly modified to suit the research setting of project work and encompassed practices of sharing reports, training and development programs, IT systems and general encouragement to share knowledge among project team members.

Tacit knowledge sharing measurement scale was assessed with items from Wang and Wang (2012) who had constructed it by linking items from different studies (Bock, Zmud, Kim, \& Lee, 2005; Holste \& Fields, 2010; C.P. Lin,2007; H.F. Lin, 2007; Reychav \& Weisberg, 2010). Again we adjusted the item wording to fit the context of project member interaction and knowledge sharing context. Used items refer to project member experience, know-where and know-who, expertize and lessons learned from failed projects.

\section{Data analysis and results}

\subsection{Descriptive statistics and reliability}

Descriptive statistics for Explicit knowledge sharing, Tacit knowledge sharing and Team performance are shown in table 1.

Explicit knowledge sharing measure ranged across the whole possible range of values [1.00, 7.00], with mean 5.46 (95\% confidence interval: $[5.35,5.56])$ and median 5.50. Tacit knowledge sharing measure had taken values between 1.57 and 7, with the mean 5.77 (95\% confidence interval: [5.67, 5.88]) and median 5.86. Team performance measure had values in $[1.75,7.00]$ range, with mean 5.24 (95\% confidence interval: [5.13, 5.34]) and median 5.25 .

Normality tests (Kolmogorov - Smirnov and Shapiro - Wilk) were performed on data. The results are shown in Table 2. In those tests, null hypothesis is that data is normally distributed. So, if the obtained coefficients are not significant, null hypothesis that data fits the normal distribution well cannot be rejected. According to the results of both normality tests, explicit knowledge sharing measure, tacit knowledge sharing measure and team performance measure fit the normal distribution reasonably well. Normality has been further assessed using the Q-Q' plots for explicit knowledge sharing (Figure 1), tacit knowledge sharing (Figure 2) and Team performance (Figure 3). For normally distributed data, Q-Q' plot should be approximately linear. All the plots support the claim that the data fits the normal distribution reasonably well for all three observed variables.

Reliability of the data was assessed using the Cronbach alpha coefficients. Cronbach alpha coefficients over 0.7 are considered acceptable. Global Cronbach alpha coefficient of 0.825 was obtained, and Item-total statistics, including Cronbach alpha coefficients if item deleted were calculated (Table 3). The results indicate that data reliability is at an acceptable level. 
Table 5. Descriptive statistics for Team performance, explicit and tacit knowledge.

\begin{tabular}{|c|c|c|c|c|}
\hline \multicolumn{5}{|c|}{ Descriptives } \\
\hline & & & Statistic & Std. Error \\
\hline \multirow[t]{7}{*}{ Explicit knowledge } & \multicolumn{2}{|l|}{ Mean } & 5.4598 & .05465 \\
\hline & \multirow[t]{2}{*}{$95 \%$ Confidence Interval for Mean } & Lower Bound & 5.3522 & \\
\hline & & Upper Bound & 5.5673 & \\
\hline & \multicolumn{2}{|l|}{ Median } & 5.5000 & \\
\hline & \multicolumn{2}{|l|}{ Std. Deviation } & .96836 & \\
\hline & \multicolumn{2}{|l|}{ Minimum } & 1.00 & \\
\hline & \multicolumn{2}{|l|}{ Maximum } & 7.00 & \\
\hline \multirow[t]{7}{*}{ Tacit knowledge } & \multicolumn{2}{|l|}{ Mean } & 5.7746 & .05103 \\
\hline & \multirow[t]{2}{*}{$95 \%$ Confidence Interval for Mean } & Lower Bound & 5.6742 & \\
\hline & & Upper Bound & 5.8750 & \\
\hline & \multicolumn{2}{|l|}{ Median } & 5.8571 & \\
\hline & \multicolumn{2}{|l|}{ Std. Deviation } & .90428 & \\
\hline & \multicolumn{2}{|l|}{ Minimum } & 1.57 & \\
\hline & \multicolumn{2}{|l|}{ Maximum } & 7.00 & \\
\hline \multirow[t]{7}{*}{ Team performance } & \multicolumn{2}{|l|}{ Mean } & 5.2367 & .05356 \\
\hline & \multirow[t]{2}{*}{ 95\% Confidence Interval for Mean } & Lower Bound & 5.1313 & \\
\hline & & Upper Bound & 5.3421 & \\
\hline & \multicolumn{2}{|l|}{ Median } & 5.2500 & \\
\hline & \multicolumn{2}{|l|}{ Std. Deviation } & .94917 & \\
\hline & \multicolumn{2}{|l|}{ Minimum } & 1.75 & \\
\hline & \multicolumn{2}{|l|}{ Maximum } & 7.00 & \\
\hline
\end{tabular}

Table 6. Normality test results on Explicit knowledge sharing, Tacit knowledge sharing and Team performance data

\begin{tabular}{|l|r|r|}
\hline & $\begin{array}{c}\text { Kolmogorov } \\
- \text { Smirnov }^{\mathrm{a}}\end{array}$ & $\begin{array}{c}\text { Shapiro- } \\
\text { Wilk }^{-}\end{array}$ \\
\hline Explicit knowledge & .117 & .951 \\
\hline Tacit knowledge & .110 & .924 \\
\hline Team performance & .112 & .969 \\
\hline
\end{tabular}

Table 7. Reliability analysis: item - total statistics.

\begin{tabular}{|l|c|c|c|c|c|}
\hline & $\begin{array}{c}\text { Scale Mean } \\
\text { if Item } \\
\text { Deleted }\end{array}$ & $\begin{array}{c}\text { Scale } \\
\text { Variance if } \\
\text { Item Deleted }\end{array}$ & $\begin{array}{c}\text { Corrected Item- } \\
\text { Total } \\
\text { Correlation }\end{array}$ & $\begin{array}{c}\text { Squared } \\
\text { Multiple } \\
\text { Correlation }\end{array}$ & $\begin{array}{c}\text { Cronbach's } \\
\text { Alpha if Item } \\
\text { Deleted }\end{array}$ \\
\hline $\begin{array}{l}\text { Explicit } \\
\text { knowledge }\end{array}$ & 11.0113 & 2.649 & .736 & .584 & .702 \\
\hline $\begin{array}{l}\text { Team } \\
\text { performance }\end{array}$ & 11.2343 & 3.056 & .588 & .345 & .851 \\
\hline $\begin{array}{l}\text { Tacit } \\
\text { knowledge }\end{array}$ & 10.6965 & 2.858 & .729 & .576 & .714 \\
\hline
\end{tabular}




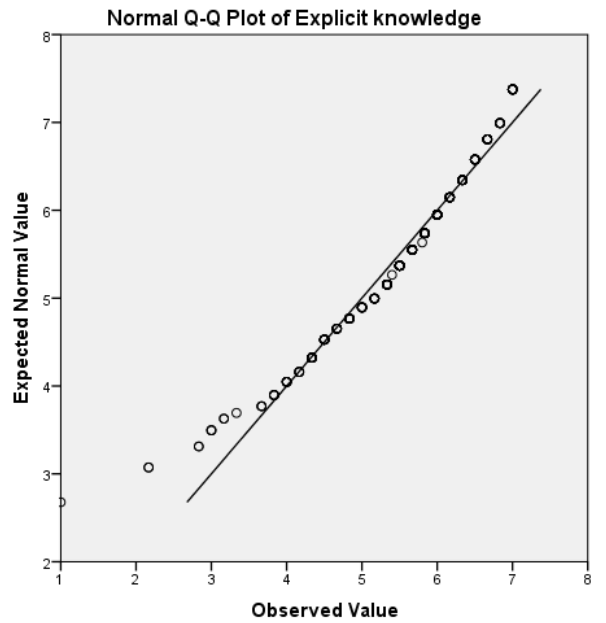

Figure 3. Normal Q-Q' plot of explicit knowledge sharing.



Figure 4. Normal Q-Q' plot of tacit knowledge sharing.



Figure 5. Normal Q-Q' plot of team performance. 


\subsection{Correlation analysis and validity}

Mutual correlation coefficients are shown in Table 3. As expected, input variable explicit knowledge sharing and tacit knowledge sharing are moderately positively mutually correlated, as well as moderately positively correlated with the measured outcome variable Team performance. Correlation coefficient $\mathrm{r}=0.74$ between explicit and tacit knowledge sharing was obtained. Correlations coefficients $r=0.56$ and $r=0.54$ for the correlation between explicit and tacit knowledge with team performance respectively). All the correlations were statistically significant $(\mathrm{p}<0.001)$.

Table 4. Mutual correlation coefficients between Explicit knowledge sharing, Tacit knowledge sharing and Team performance

\begin{tabular}{|c|c|c|c|c|}
\hline \multicolumn{5}{|c|}{ Correlations $^{b}$} \\
\hline & & $\begin{array}{c}\text { Explicit } \\
\text { knowledge }\end{array}$ & Tacit knowledge & Team performance \\
\hline \multirow[t]{2}{*}{ Explicit knowledge } & Pearson Correlation & 1 & $.742^{*}$ & $.555^{* *}$ \\
\hline & Sig. (2-tailed) & & .000 & .000 \\
\hline \multirow[t]{2}{*}{ Tacit knowledge } & Pearson Correlation & $.742^{* *}$ & 1 & $.542^{* *}$ \\
\hline & Sig. (2-tailed) & .000 & & .000 \\
\hline \multirow[t]{2}{*}{ Team performance } & Pearson Correlation & $.555^{* * *}$ & $.542^{* *}$ & 1 \\
\hline & Sig. (2-tailed) & .000 & .000 & \\
\hline
\end{tabular}

Obtained positive correlations between all three observed measures confirm the theoretical expectations and thus confirm convergent validity. Construct validity was further assessed using factor analysis. A single factor was extracted, explaining majority of variance in the data, so no rotation was performed (Table 5). Table 6 shows the obtained results of Kaiser-Meyer-Olkin and Bartlett's tests of sampling accuracy. Kaiser-Meyer-Olkin measure of sampling adequacy of 0.686 further confirms construct validity (values greater than 0.6 are considered good). A single factor was extracted, so no rotation was performed.

Table 8. Component extraction results

\begin{tabular}{|c|c|c|c|c|c|c|}
\hline \multicolumn{7}{|c|}{ Total Variance Explained } \\
\hline \multirow[b]{2}{*}{ Component } & \multicolumn{3}{|c|}{ Initial Eigenvalues } & \multicolumn{3}{|c|}{ Extraction Sums of Squared Loadings } \\
\hline & Total & $\begin{array}{c}\% \text { of } \\
\text { Variance }\end{array}$ & Cumulative $\%$ & Total & $\begin{array}{c}\% \text { of } \\
\text { Variance }\end{array}$ & Cumulative $\%$ \\
\hline 1 & 2.231 & 74.363 & 74.363 & 2.231 & 74.363 & 74.363 \\
\hline 2 & .512 & 17.061 & 91.424 & & & \\
\hline 3 & .257 & 8.576 & 100.000 & & & \\
\hline
\end{tabular}

Table 9. Tests of sampling adequacy

\begin{tabular}{|l|l|r|}
\hline \multicolumn{2}{|c|}{ KMO and Bartlett's Test } \\
\hline Kaiser-Meyer-Olkin Measure of Sampling Adequacy. & .686 \\
\hline \multirow{2}{*}{ Bartlett's Test of Sphericity } & Approx. Chi-Square & 381.170 \\
\cline { 2 - 3 } & Df & 3 \\
\cline { 2 - 3 } & Sig. & .000 \\
\hline
\end{tabular}

\subsection{Regression analysis}

In order to further elucidate and quantitatively express the influence of explicit and tacit knowledge on team performance, regression analysis of the effects of explicit knowledge and tacit knowledge on team performance, 
using multiple linear regression in SPSS. Since data fit the normal distribution reasonably well, use of linear regression was justified.

Table 7 shows quality of the fit parameters. Predictive power of the model, expressed by the adjusted $\mathrm{R}^{2}$ value is 0.341 . Moderately small percentage of variance in team performance can be explained by varying explicit and tacit knowledge sharing, suggesting that additional effects unaccounted for by the model are present.

Results of the regression analysis are shown in Table 8. Predictive relationship between Team performance as an outcome and explicit and tacit knowledge is given by the following equation:

$\mathrm{TP}=0.33 *$ Explicit $+0.30 *$ Tacit +1.66

Both regression coefficients for explicit knowledge sharing and tacit knowledge sharing as independent predictors are highly statistically significant (mean $0.33, \mathrm{p}<0.001,95 \%$ confidence interval $[0.20,0.47]$ for explicit knowledge sharing and mean $0.30, \mathrm{p}<0.001,95 \%$ confidence interval $[0.16,0.45]$ for tacit knowledge sharing respectively). Therefore, theoretical model has been justified by the regression results. Positive linear relationship between explicit knowledge was confirmed, where one unit increase in the measure of explicit knowledge sharing results in 0.33 units of increase in team performance measure, given constant tacit knowledge sharing measure. Additionally, positive linear relationship between tacit knowledge and team performance, where a unit increase in tacit knowledge sharing measure results in the increase of team performance measure by 0.30 , given constant explicit knowledge sharing measure, was detected.

Table 10. Predictive power measures of the obtained multiple linear regression model.

\begin{tabular}{|c|c|c|c|c|c|c|c|c|}
\hline \multirow[b]{2}{*}{ Model } & \multirow[b]{2}{*}{$\mathrm{R}$} & \multirow[b]{2}{*}{$\begin{array}{c}\mathrm{R} \\
\text { Square }\end{array}$} & \multirow[b]{2}{*}{$\begin{array}{c}\text { Adjusted R } \\
\text { Square }\end{array}$} & \multirow{2}{*}{$\begin{array}{l}\text { Std. Error } \\
\text { of the } \\
\text { Estimate }\end{array}$} & & & & \\
\hline & & & & & $\begin{array}{l}\text { R Square } \\
\text { Change }\end{array}$ & F Change & df1 & $\begin{array}{l}\text { Sig. F } \\
\text { Change }\end{array}$ \\
\hline 1 & $.588^{\mathrm{a}}$ & .345 & .341 & .77044 & .345 & 82.031 & 2 & .000 \\
\hline
\end{tabular}

Table 8. Multiple linear regression coefficients.

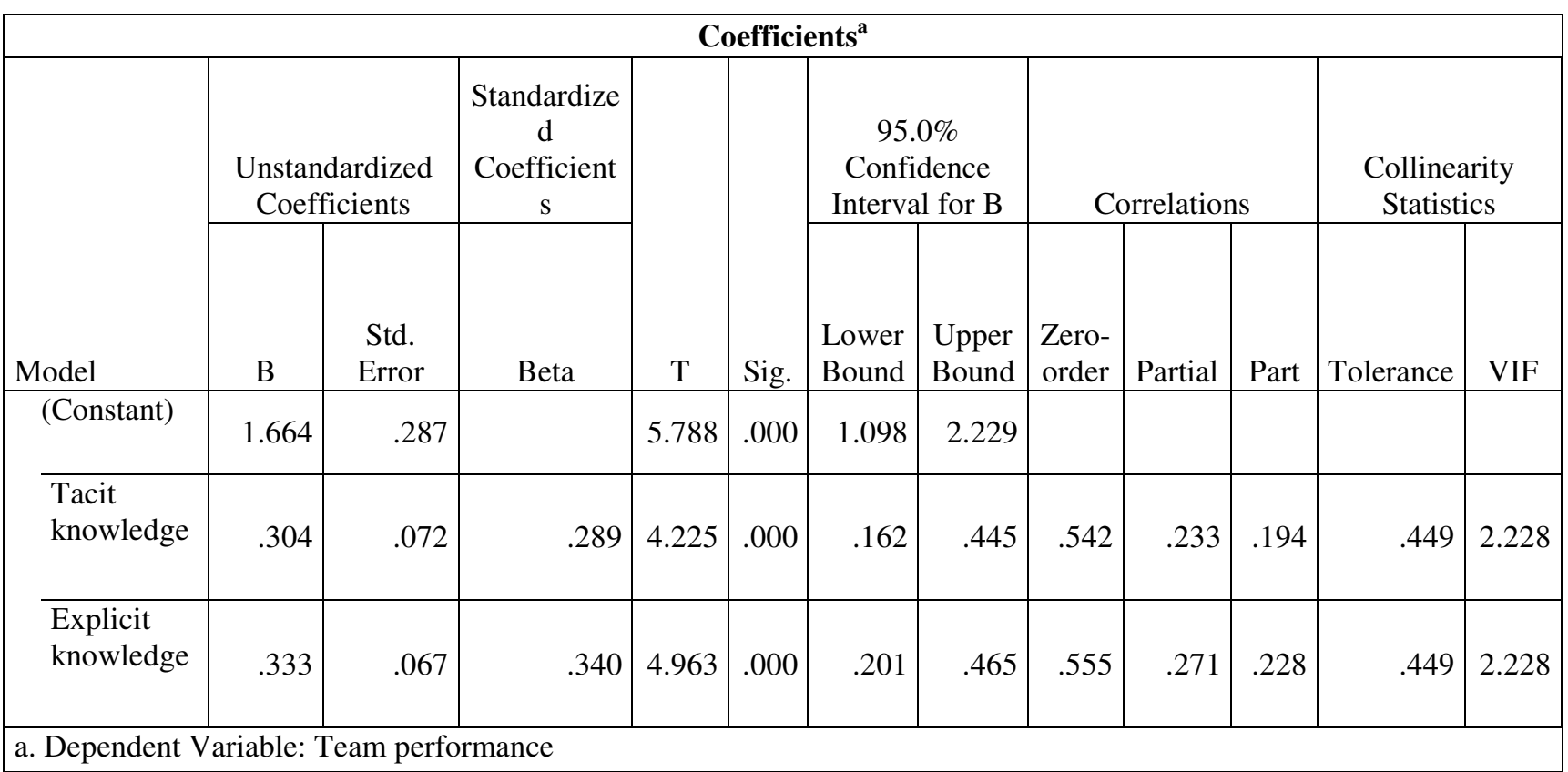

\subsection{Analysis of the proposed hypotheses}

5.3.1. Sharing of tacit knowledge positively influences Team performance

Null hypothesis is defined as H0:=Team performance is not positively influenced by sharing of tacit knowledge. Since the mean regression coefficient for the effect of tacit knowledge sharing on team performance is 0.30 , with 
$95 \%$ confidence interval in range $[0.16,0.45]$, null hypothesis can be rejected at $\mathrm{p}<0.001$. Therefore, we can conclude that sharing of tacit knowledge positively influences Team performance.

\subsubsection{Sharing of explicit knowledge positively influences Team performance}

Null hypothesis is defined as H0:=Team performance is not positively influenced by sharing of explicit knowledge. Since the mean regression coefficient for the effect of explicit knowledge sharing on team performance is 0.33 , with $95 \%$ confidence interval in range $[0.20,0.45]$, null hypothesis can be rejected at $\mathrm{p}<0.001$. Therefore, we can conclude that sharing of explicit knowledge positively influences Team performance.

\subsubsection{Tacit knowledge sharing level between scientists is high}

Null hypothesis is defined as H0:=Tacit knowledge sharing level between scientists is not high (where not high would be defined as measure levels lower than 5). Since the mean of Tacit knowledge sharing is 5.77, with 95\% confidence interval in range $[5.67,5.88]$, null hypothesis can be rejected at $p<0.001$. Therefore, we can conclude that tacit knowledge sharing level between scientists is high.

\subsubsection{Explicit knowledge sharing between scientists is high}

Null hypothesis is defined as H0:=Explicit knowledge sharing level between scientists is not high (where not high would be defined as measure levels lower than 5). Since the mean of explicit knowledge sharing is 5.46, with $95 \%$ confidence interval in range [5.35, 5.56], null hypothesis can be rejected at $p<0.001$. Therefore, we can conclude that explicit knowledge sharing level between scientists is high.

\subsubsection{Team performance is high}

Null hypothesis is defined as H0:=Team performance is not high (where not high would be defined as measure levels lower than 5). Since the mean of team performance is 5.24, with $95 \%$ confidence interval in range [5.13, 5.34], null hypothesis can be rejected at $\mathrm{p}<0.05$. Therefore, we can conclude that team performance is high.

\subsubsection{Sharing of tacit knowledge positively influences Team performance}

Null hypothesis is defined as H0:=Team performance is not positively influenced by sharing of tacit knowledge. Since the mean regression coefficient for the effect of tacit knowledge sharing on team performance is 0.30 , with $95 \%$ confidence interval in range $[0.16,0.45]$, null hypothesis can be rejected at $p<0.001$. Therefore, we can conclude that sharing of tacit knowledge positively influences Team performance.

\subsubsection{Sharing of explicit knowledge positively influences Team performance}

Null hypothesis is defined as H0:=Team performance is not positively influenced by sharing of explicit knowledge. Since the mean regression coefficient for the effect of explicit knowledge sharing on team performance is 0.33 , with $95 \%$ confidence interval in range [0.20, 0.45], null hypothesis can be rejected at $\mathrm{p}<0.001$. Therefore, we can conclude that sharing of explicit knowledge positively influences Team performance.

\section{Discussion}

Our findings are in line with what was found in prior studies, indicating that knowledge sharing exerts positive influence on team performance. In our study both tacit and explicit knowledge are significant for team performance. Teams that share knowledge freely and openly tend to be more effective. For that reason, research and academic institutions should emphasize the importance of knowledge sharing and apply management initiatives aimed at facilitating knowledge sharing. Effective knowledge sharing attained through proper management of various factors leads to a better team performance and other positive outcomes of the project. Principles of uniqueness and openness in regard to explicit knowledge sharing contribute to the team performance. (Nahapiet \& Ghoshal, 1998). Furthermore, demonstrability, cooperation and discussion structure were found to enhance explicit knowledge sharing and informational interdependence, information distribution and team member heterogeneity were found to negatively affect knowledge sharing (Mortensen \& Hinds, 2001).

Managers' efforts should be aimed at generating knowledge sharing conditions through leadership (Zollo \& Winter, 2002) and various organizational mechanisms. For instance, fair treatment of employees, empowerment and carefully applied incentives can all be implemented to create the conditions conducive to fostering a knowledge sharing environment. Furthermore, when creating management initiatives managers should take into consideration personal dispositions of teams and individuals, as personality and attitude play an important role in generating behavioral outcomes. 
In the socialization process effort is not being put in converting explicit into tacit knowledge. Information technology should therefore be aimed at facilitating socialization process and not in making tacit knowledge explicit. In recent years 2.0. technologies have emerged which are characterized by the richness of the media and might be more suitable for effective socialization process facilitated by IT. Through video tutorials, abundant internet learning resources and social networks that provide communities of practice a platform for intensive communication and idea exchange can all lead to improved team performance.

As for governments financing policy, it should be adjusted to types of projects. In industries that possess a synthetic or symbolic knowledge base knowledge exchange in geographical closeness is highly significant because the interpretation of the knowledge has a tendency to vary between places, unlike in those industries with analytical knowledge base where knowledge is codified, more abstract and universal (Martin, Roman, and Jerker Moodysson, 2013). In order to increase the mobility of scientists and ensure there is sufficient face-to-face contact needed for effective knowledge exchange they should be doing so by keeping in mind the industry in question and nature of work.

Additionally, team performance and sharing of both tacit and explicit knowledge between scientists are on high levels, indicating that scientists working on projects engage in sharing of explicit knowledge such as information, data, product samples, materials, equipment and instruments despite their diverse characteristics and challenging environment. Having a limited face-to-face time as well as tacit knowledge embedded in people and facilitated through the exchange of team members and other technical experts of global teams. Through faceto face communication, electronic networks and other information technology it is possible to exchange knowledge essential to the success of the project. When it comes to distributed research and development process (Ahuja et al., 2000) and teams whose members are geographically spread; knowledge flows are enabled by properly utilized electronic networks and other computer mediated communication tools. Actually, experts with diverse backgrounds and training integrating information are more likely to reach quality solutions on complex projects (Mesmer-Magnus \& DeChurch, 2009).

By gaining access to expertise, ideas and information which are not available locally to project team members, they can benefit greatly by enhancing their knowledge base which in turn will improve team performance and drive innovation.

\section{Conclusion}

In so far, knowledge sharing has been tied to team performance in many instances, still in the context of scientific cooperation this investigation has not been attempted. Furthermore, the division of tacit and explicit knowledge sharing is required, as they are quite different in nature, and as they might not contribute to the team performance equally. This study, aimed to explore knowledge sharing between the project team members and to explain influence sharing of tacit and explicit knowledge have on team performance. In the attempt to achieve this goal we analyzed knowledge sharing between scientists, drawing lessons from government funded research projects.

Through the development of a framework an understanding of the relationships between sharing of tacit and explicit knowledge sharing and team performance, in research project teams, had been achieved. In addition, we provided a first analysis of the current state of knowledge sharing on research projects in Croatia. The outcomes of this study shed light on knowledge sharing behavior between researchers, therefore, contributing towards the successful implementation of knowledge sharing initiatives as part of research project knowledge management as well as organizational knowledge management initiatives.

\section{References}

Adenfelt, M. (2010). Exploring the performance of transnational projects: shared knowledge, coordination and communication. International Journal of Project Management, 28(6), 529-538.

Ahuja, G. (2000). The duality of collaboration: Inducements and opportunities in the formation of interfirm linkages. Strategic management journal, 21(3), 317-343.

Alavi, M. (2000). Managing organizational knowledge. Framing the domains of IT management: Projecting the future through the past, 15-28. 
Alavi, M., \& Leidner, D. E. (2001). Review: Knowledge management and knowledge management systems: Conceptual foundations and research issues. MIS quarterly, 107-136.

Argote, L., \& Ingram, P. (2000). Knowledge transfer: A basis for competitive advantage in firms. Organizational behavior and human decision processes, 82(1), 150-169.

Au, Y., \& Marks, A. (2012). "Virtual teams are literally and metaphorically invisible": Forging identity in culturally diverse virtual teams. Employee Relations, 34(3), 271-287.

Barry, B., \& Stewart, G. L. (1997). Composition, process, and performance in self-managed groups: the role of personality. Journal of Applied Psychology, 82(1), 62.

Beal, D. J., Cohen, R. R., Burke, M. J., \& McLendon, C. L. (2003). Cohesion and performance in groups: a meta-analytic clarification of construct relations. Journal of Applied Psychology, 88(6), 989.

Becerra-Fernandez, I., \& Sabherwal, R. (2001). Organizational knowledge management: A contingency perspective. Journal of management information systems, 18(1), 23-56.

Berman, S. L., Down, J., \& Hill, C. W. (2002). Tacit knowledge as a source of competitive advantage in the National Basketball Association. Academy of Management Journal, 45(1), 13-31.

Bock, G. W., Zmud, R. W., Kim, Y. G., \& Lee, J. N. (2005). Behavioral intention formation in knowledge sharing: Examining the roles of extrinsic motivators, social-psychological forces, and organizational climate. MIS quarterly, 87-111.

Choi, S. Y., Lee, H., \& Yoo, Y. (2010). The Impact of Information Technology and Transactive Memory Systems on Knowledge Sharing, Application, and Team Performance: A Field Study. MIS quarterly, 34(4).

Cohen, Susan G., and Diane E. Bailey. "What makes teams work: Group effectiveness research from the shop floor to the executive suite." Journal of management 23.3 (1997): 239-290.

Conner, K. R., \& Prahalad, C. K. (1996). A resource-based theory of the firm: Knowledge versus opportunism. Organization science, 7(5), 477-501.

Cross, R., \& Cummings, J. N. (2004). Tie and network correlates of individual performance in knowledgeintensive work. Academy of Management Journal, 47(6), 928-937.

Davenport, T., \& Prusak, L. (1998). Working Knowledge: Hire people who can create knowledge. Executive Excellence, 15, 10-10.

Dyer, J., \& Nobeoka, K. (2002). Creating and managing a high performance knowledge-sharing network: the Toyota case.

Faraj, S., \& Sproull, L. (2000). Coordinating expertise in software development teams. Management science, 46(12), 1554-1568.

Fassbender, E., Richards, D., Bilgin, A., Thompson, W. F., \& Heiden, W. (2012). VirSchool: The effect of background music and immersive display systems on memory for facts learned in an educational virtual environment. Computers \& Education, 58(1), 490-500.

Gibson, C. B., \& Gibbs, J. L. (2006). Unpacking the concept of virtuality: The effects of geographic dispersion, electronic dependence, dynamic structure, and national diversity on team innovation. Administrative Science Quarterly, 51(3), 451-495.

Grant, R. M. (1996). Toward a knowledge-based theory of the firm. Strategic management journal, 17, 109-122.

Greenhalgh, L., \& Chapman, D. I. (1998). Negotiator relationships: Construct measurement, and demonstration of their impact on the process and outcomes of negotiation. Group Decision and Negotiation, 7(6), 465-489.

Hansen, M. T. (2002). Knowledge networks: Explaining effective knowledge sharing in multiunit companies. Organization science, 13(3), 232-248. 
Hansen, M. T., \& Haas, M. R. (2001). Competing for attention in knowledge markets: Electronic document dissemination in a management consulting company. Administrative Science Quarterly, 46(1), 1-28.

Holste, J. S., \& Fields, D. (2010). Trust and tacit knowledge sharing and use.Journal of Knowledge Management, 14(1), 128-140.

Howells, J. (1996). Tacit knowledge. Technology analysis \& strategic management, 8(2), 91-106.

Jackson, S. E., Chuang, C. H., Harden, E. E., \& Jiang, Y. (2006). Toward developing human resource management systems for knowledge-intensive teamwork. Research in personnel and human resources management, 25, 27-70.

Jarvenpaa, S. L., \& Majchrzak, A. (2008). Knowledge collaboration among professionals protecting national security: Role of transactive memories in ego-centered knowledge networks. Organization Science, 19(2), 260276.

Jeng, B. C., \& Liang, T. P. (1995). Fuzzy indexing and retrieval in case-based systems. Expert Systems with Applications, 8(1), 135-142.

Kanawattanachai, P., \& Yoo, Y. (2002). Dynamic nature of trust in virtual teams. The Journal of Strategic Information Systems, 11(3), 187-213.

Käser, P. A., \& Miles, R. E. (2002). Understanding knowledge activists' successes and failures. Long Range Planning, 35(1), 9-28.

Kogut, B., \& Zander, U. (1992). Knowledge of the firm, combinative capabilities, and the replication of technology. Organization science, 3(3), 383-397.

Koskinen, K. U., Pihlanto, P., \& Vanharanta, H. (2003). Tacit knowledge acquisition and sharing in a project work context. International journal of project management, 21(4), 281-290.

Lewis, K. (2004). Knowledge and performance in knowledge-worker teams: A longitudinal study of transactive memory systems. Management science, 50(11), 1519-1533.

Liebowitz, S. J., \& Margolis, S. E. (1999). Winners, Losers \& Microsoft; Competition and Antitrust in High Technology. Independent Institute.

Lin, H. F. (2007). Effects of extrinsic and intrinsic motivation on employee knowledge sharing intentions. Journal of information science, 33(2), 135-149.

Marks, M. A., Zaccaro, S. J., \& Mathieu, J. E. (2000). Performance implications of leader briefings and teaminteraction training for team adaptation to novel environments. Journal of Applied Psychology, 85(6), 971.

Martin, R., \& Moodysson, J. (2013). Comparing knowledge bases: on the geography and organization of knowledge sourcing in the regional innovation system of Scania, Sweden. European Urban and Regional Studies, 20(2), 170-187.

Mesmer-Magnus, J. R., \& DeChurch, L. A. (2009). Information sharing and team performance: a metaanalysis. Journal of Applied Psychology, 94(2), 535.

Mortensen, M., \& Hinds, P. J. (2001). Conflict and shared identity in geographically distributed teams. International Journal of Conflict Management, 12(3), 212-238.

Nahapiet, J., \& Ghoshal, S. (1998). Social capital, intellectual capital, and the organizational advantage. Academy of management review, 23(2), 242-266.

Nonaka, I., Byosiere, P., Borucki, C. C., \& Konno, N. (1994). Organizational knowledge creation theory: a first comprehensive test. International Business Review, 3(4), 337-351.

Osterloh, M., \& Frey, B. S. (2000). Motivation, knowledge transfer, and organizational forms. Organization science, 11(5), 538-550. 
Pawlowski, S. D., \& Robey, D. (2004). Bridging user organizations: Knowledge brokering and the work of information technology professionals. MIS quarterly, 645-672.

Politis, J. D. (2003). The connection between trust and knowledge management: what are its implications for team performance. Journal of knowledge management, 7(5), 55-66.

Reychav, I., \& Weisberg, J. (2009). Going beyond technology: Knowledge sharing as a tool for enhancing customer-oriented attitudes. International Journal of Information Management, 29(5), 353-361.

Reychav, I., \& Weisberg, J. (2010). Bridging intention and behavior of knowledge sharing. Journal of Knowledge Management, 14(2), 285-300.

Rico, R., Sánchez-Manzanares, M., Gil, F., \& Gibson, C. (2008). Team implicit coordination processes: A team knowledge-based approach. Academy of Management Review, 33(1), 163-184.

Schepers, P., \& Van den Berg, P. T. (2007). Social factors of work-environment creativity. Journal of Business and Psychology, 21(3), 407-428.

Schittekatte, M., \& Van Hiel, A. (1996). Effects of partially shared information and awareness of unshared information on information sampling. Small Group Research, 27(3), 431-449.

Small, C. T., \& Sage, A. P. (2006). Knowledge management and knowledge sharing: A review. Information, Knowledge, Systems Management, 5(3), 153-169.

Stewart, G. (1997). Supply-chain operations reference model (SCOR): the first cross-industry framework for integrated supply-chain management. Logistics information management, 10(2), 62-67.

Wegner, D. M., Schneider, D. J., Carter, S. R., \& White, T. L. (1987). Paradoxical effects of thought suppression. Journal of personality and social psychology, 53(1), 5. 
The IISTE is a pioneer in the Open-Access hosting service and academic event management. The aim of the firm is Accelerating Global Knowledge Sharing.

More information about the firm can be found on the homepage:

http://www.iiste.org

\section{CALL FOR JOURNAL PAPERS}

There are more than 30 peer-reviewed academic journals hosted under the hosting platform.

Prospective authors of journals can find the submission instruction on the following page: http://www.iiste.org/journals/ All the journals articles are available online to the readers all over the world without financial, legal, or technical barriers other than those inseparable from gaining access to the internet itself. Paper version of the journals is also available upon request of readers and authors.

\section{MORE RESOURCES}

Book publication information: http://www.iiste.org/book/

Recent conferences: http://www.iiste.org/conference/

\section{IISTE Knowledge Sharing Partners}

EBSCO, Index Copernicus, Ulrich's Periodicals Directory, JournalTOCS, PKP Open Archives Harvester, Bielefeld Academic Search Engine, Elektronische Zeitschriftenbibliothek EZB, Open J-Gate, OCLC WorldCat, Universe Digtial Library, NewJour, Google Scholar



